\title{
Language as means and as an obstacle of communication. Phenomenological grounds for intercultural understanding
}

\author{
Dieter Lohmar \\ Husserl-Archiv der Universität zu Köln \\ dieter.lohmar@uni-koeln.de
}

Fecha de recepción: 26-2-2016

Fecha de aceptación: 24-5-2016

\begin{abstract}
In this article I will establish the concept of a "symbolic system of representation" to make clear how it is possible that humans are not only using the language-based system of representation for cognitive contents. A system of representation should enable us to "think", i.e. to form and manipulate an idea of a state of affairs or of an event without having the appropriate intuition of them. We believe that we do this mostly in language. My thesis is that there are non-linguistic systems of representation with the same performance. We simultaneously use different systems of representation; the most prominent are language, gestures, feelings, and scenic images. Phenomenological analysis reveals that it is especially fruitful to investigate into the scenic mode of daydreaming as a central form of non-linguistic thinking. By close comparison of non-linguistic systems of representation and non-linguistic communication, their common ground in similarity semantics is revealed. This is the principal basis to begin and maintain intercultural understanding across the borders of national languages.
\end{abstract}

Keywords: representation; language; non-linguistic thinking; phenomenology; communication; interculturality

Resum. El llenguatge com a mitjà i com a obstacle de la comunicació: Bases fenomenològiques per a la comprensió intercultural

En aquest article parlaré del concepte de sistema simbòlic de la representació per tal d'aclarir com és possible que els éssers humans no només fem servir el llenguatge per expressar continguts cognitius. Un sistema de representació ens ha de permetre «pensar», és a dir, formar-nos i manipular una idea sobre un estat de coses o una situació sense tenir-ne una intuïció apropiada. Les persones creiem que ens comuniquem sobretot utilitzant el llenguatge, però la meva tesi és que hi ha diferents sistemes no lingüístics de representació que ofereixen el mateix rendiment i que fem servir simultàniament; els més destacats són: el llenguatge, els gestos, els sentiments i les imatges escèniques. L'anàlisi fenomenològica revela que és especialment fructífer investigar en el mode escènic de l'estat de somni com un aspecte central del pensament no lingüístic. Mitjançant una comparació minuciosa entre els sistemes no lingüístics de representació i la comunicació no lingüística, es revela 
com a base comuna la similitud semàntica, que constitueix el fonament principal per iniciar i mantenir l'entesa intercultural a través de les fronteres dels idiomes nacionals.

Paraules clau: imatge; llenguatge; pensament no lingüístic; fenomenologia; comunicació; interculturalitat

\section{Sumario}

1. Natural differences of regional languages as an obstacle of understanding

2. The idea of a close connection between thinking and language

3. Some basics of Husserl's theory of cognition and meaning
5. The hand and feet system of communication

6. The system of scenic phantasma

Bibliographical references

4. What are the alternatives for symbolic representations in non-linguistic thinking?

\section{Natural differences of regional languages as an obstacle of understanding}

In communities, all forms of communication are ruled by conventions. This usually leads to the result of a very special style of using language in small communities, up to the special dialect. By this process a difference to the neighbouring communities generates, and the resulting regional language style becomes a distinguishing mark for the community. But this process - I will call it "making differences to the neighbours" - leads even further to the development of completely different languages. So what starts out as a perfect means for communication ends up becoming an obstacle to communication between even small neighbouring communities.

We might object that there are major national languages that allow for understanding in large nations. But we have to admit that these national languages are usually more like a second language and not a mother tongue. Thus we have to realize that even major national languages are only names for many regionally different languages, developed up to the point that their users usually cannot understand each other. Thus, language as an excellent means of understanding within a small community evolves from out of a process of "making differences to the neighbours" all the way to becoming a distinguished mark of the identity of a small community. And so making differences, in the end it becomes an obstacle of understanding with other communities.

We might simply accept these differences in everyday culture, in values and in the meaning of the words, and even in the local slang used as a sheer fact - but we can also acknowledge some explanations. It is difficult to determine the reason for the process of "making differences to the neighbours". Even if 
we do not have to accept mythological or religious explanations of the radical differences of languages. In my view, the process of making-differences between neighbouring communities seems to be more like a natural development. For example, we find the tendency to use the formation of a system of communication (gestures, signs, actions, etc.) as a group's mark of identity already in chimpanzee communities. Chimpanzees develop a special style of welcome gesture, specific for their group and this - besides the knowledge of all members of the group - becomes a mark of their identity.

This behaviour is quite similar in highly cerebralized mammals and in humans. The evolutionary background for the behaviour of "making differences" which sets a group apart from other groups consists in cooperation and altruism. I will try to describe this behaviour from the point of view of a member of a primate group, such that there is an "innermost circle" with the highest degree of altruism limited by genetic relationship. The next circle is defined by the small group of persons I know well and I am interacting with. Here I can expect that a favour will surely be returned. I feel attached to this group, perhaps there is also a feeling of a "We". Across this border there are other groups of the same species but I feel them to be they. Moreover, we usually live in competition for food with them. In highly cooperative species the competition runs between groups. If a member of other groups crosses the border of our territory he will be attacked and hurt. This is even true in chimpanzee communities like Jane Goodall reported. ${ }^{1}$ My "we"-group is in serious competition for food with these other groups. Thus we see the good evolutionary argument for making-differences in social culture and also in the style of communication: We easily gain the possibility to differ from other groups that are competing with "us" for food.

We might even speak of a universal law in this concern: The stronger the tendency of a species for cooperation and altruism is developed within its own community, the stronger its tendency to make differences to other communities. And we know from recent comparative psychology that humans are the most cooperative and altruistic species we know of. ${ }^{2}$ Thus making differences in languages is a natural result of the altruistic and cooperative nature of humans.

What we think to be uniform national languages are only second languages of a number of people of a larger group. This attaching to a common language is only done under the influence of political considerations. And we agree to this uniformization of our language communication only in so far as we feel obliged to this bigger group often called nation, while at the same time we are engaged in making-differences in local languages. So there is always a fight between centrifugal and centripetal forces in the development of local cultural differences and local and national languages.

1. There are real wars between neighbouring groups as J. Goodall and others are reporting, $c f$. Paul, 1998: 63-66.

2. $C f$., for example, the investigations of $\mathrm{M}$. Tomasello on the high degree of readiness for cooperation in humans, $c f$. Tomasello, 2009. 
Following this insight into the natural process of developing different languages we have to ask a question of central importance: How are we able to overcome serious obstacles of understanding in the case of understanding other cultures?

Before I return to this problem, I will discuss some questions concerning a further thesis that concerns our theme: The identity or close connection between thinking and language.

\section{The idea of a close connection between thinking and language}

There is broad belief that not only our communication but also the deeper layer of our thinking is strongly associated with language. We can find variations in the thesis of a "tight connection" of language and thinking leading up to the claim that they are identical. If this is true, there is nearly no hope for a real understanding of other cultures' members.

But there are limits to the identification of language with mental abilities in general. For example it is quite obvious that cognition works independently of language; we know that cats, dogs as well as primates can easily realize the difference between food and other things, good food and poor food, etc. Thus, on the level of cognition we are quite sure that there is only a minor influence of language.

This seems to conflict with our usual idea of thinking as a special case of cognition. Therefore it makes sense to differentiate between rather simple cases of cognition based on the immediate sensible givenness of objects and their properties, and cases of cognition of higher order like conclusions from presupposed (or hypothetical) propositions or judgements that establish relations between theories, etc. Both kinds of cognition are in principle covered by Edmund Husserl's theory of categorial intuition - because he was aiming at a theory of cognition that also covers cognition in formal mathematics - but he starts with the elementary cases that do not entail a dependence on language. Nevertheless, the degree of the influence of the conceptual framework and the national semantics turns out to be different in these higher order cognitions than in the elementary everyday cases like cognizing that a banana is ripe judging from its colour, that this book is green, that this is a tree, etc.

But this argument cannot exclude the suggestion that language makes a big difference on the level of thinking. In the following, I will discuss the question of whether all modes of thinking are necessarily done with language as a symbolic system.

The human mind is often identified with the ability to think. Let us shortly recall this faculty: Thinking is understood as the ability to revitalize cognition and by this to make use of former experience for decisions and future actions. There is a broadly spread opinion which says that human thinking is always thinking in language (Thesis 1 ).

For example, Johann Georg Hamann, Gottfried Herder, Wilhelm von Humboldt and many others are convinced that language is not only a simple 
medium of thinking: They believe that language also has a strong influence on the formation of the content of our thought. This might go so far as to believe in an influence of the regional language on the way to conceive objects and the world as a whole: Language has a decisive influence on the way we conceive the world (Thesis 2).

If we accept these two theses, a further conclusion is suggested: As we have already discussed, national languages are in fact very different; this tendency for making differences is quite natural, and language has a decisive influence on the way we conceive the world. Therefore, the contents of the respective worldviews of different cultures are basically incomparable. If this were true, there would be nearly no hope of reaching a true intercultural understanding (Thesis 3). Even if we try to play this down, at least the bond of thinking to language is a heavy burden for intercultural understanding.

But as we know, there is at least in most meetings of nations the possibility to establish an initial understanding that can be broadened step by step. So we get the impression that there must be something wrong with one of the two premises above (Theses 1 and 2).

In my contribution I would like to convince you that Thesis 1 is wrong and therefore the resulting consequence, Thesis 3 , is also not valid. I will not discuss Thesis 2 - though I think that it is also wrong. ${ }^{3}$ My conviction is that most of our thinking does not use language. It is possible to think without language, and we usually use systems of representation that are non-linguistic. My access will be a phenomenological interpretation of a non-linguistic system of representation in our own mind that allows for thinking without language. ${ }^{4}$

For this analysis I will first establish the concept of a symbolic system of representation for cognitive contents (SSR) that denotes a general idea of a performance of which our language is only one single case. Nevertheless, this general idea is best explained in the case of language: A symbolic system of representation (SSR) should enable us to form an idea of a state of affairs or of an event without having the appropriate intuition of them. Usually, human thinking uses the means of language expressions. But language is only one system of representation,

3. To avoid this conclusion, we might also try other strategies. For example: There may be a last hope in the fact that due to the historical meeting of nations in peace and war, there is usually a small overlapping in language, history and culture in neighbouring nations which may be a basis for a broadening of our understanding of the other culture (Mall, 1993, 1995; Mohanty, 1993). But there is also a counter-dynamics to this small overlapping in the development of cultures: Human communities take local culture and national speech, and even dialects, as a sign of their individual uniqueness. By this demonstrative individualization, communities tend to strengthen the differences to neighbouring nations, denying the common historical offspring or the overlapping that connect them, $c f$. Lohmar (2005)

4. On other occasions I have argued that the phenomenological theory of meaning allows for alternative forms of thinking, and that there are ways to prove the necessity of non-linguistic systems of representation in humans, $c f$. Lohmar (2008b). Additionally, we share some important ways to think with higher cerebralized animals like primates, $c f$. Lohmar (2008c). I cannot discuss these theses here but they belong to the broader context of my theory, $c f$. Lohmar (2008a). 
and we can, in principle, detect other symbolic systems of representation working in our mind that have the same or nearly the same performance.

\section{Some basics of Husserl's theory of cognition and meaning}

We have at least three levels of performances: cognition, thinking and communication. I will not investigate the level of cognition, but I presuppose that this level is quite independent of the influence of languages. In my present view, it is not at all up for reasonable discussion to deny that animals can have refined forms of cognition like knowing about the kind and qualities of fruits and other objects.

There is a refined theory of cognition in Husserlian phenomenology that I cannot deal with here though I must refer to it at least in passing. ${ }^{5}$ In view of Husserl's theory of meaning, to get a picture of the step from cognition to thinking, we have to address a decisive performance that connects the elements of a symbolic system of representation with insights into a state of affairs. Husserl's theory of meaning addresses the way we connect cognition with a symbolic representation like language. There are special acts dedicated to this connection, which Husserl calls "meaning-giving" acts (bedeutunggebende Akte). We do not only use them to find the best expression for our cognition but we also have to use them in interpreting, for example, spoken language or other symbolic ways of thinking in public communication.

I will delineate some central traits of Husserl's theory of meaning that are also based on his analyses of cognition (categorial intuition). In my view, Husserl's phenomenology offers a refined theory of meaning, and it might also serve as a basis to understand non-linguistic thinking. In other words, his theory of meaning leaves open the possibility of systems of representation for cognitive contents using means other than language. But this does not yet make it evident that humans are able to think in both modes.

We know that humans are able to think in language. But it seems not so easy to convince someone of the existence of a non-linguistic system of representation still functioning in our consciousness. In my view, we simultaneously use different systems of representation, including language, but also scenic images, gestures, and feelings. I will argue for this by providing a phenomenological analysis of the non-linguistic systems functioning in us. It is especially fruitful to investigate emerging single phantasma, series of such pictures, and the connection of these phantasmatic pictures in the scenic mode of daydreaming as a central form of non-linguistic modes of thinking. ${ }^{6}$

5. Cf. Lohmar (2002) and Lohmar (2008d).

6. We might immediately see a possible consequence that follows from the last suggestion: It is highly probable that the non-human members of the primate group might be able to think using the same non-linguistic systems of representation as we do. Perhaps we may also gain some insights about the limits of the performance of non-linguistic modes of thinking by taking into account the case of thinking, available both to humans and animals. But this is only a secondary theme of my investigation; primarily, I am interested in the way humans are thinking. 
Most basic in this regard is the insight into the function of the acts providing intuitive evidence of states of affairs, relations, etc. Husserl names this class of acts categorial intuition. This theory of cognition is quite complex, and I cannot go into much detail here. Additionally, there are other acts that connect this intuition with elements of a representational system such as language. Husserl calls these other acts meaning-giving acts. This is already an important starting point, since it suggests that language by itself is not knowledge, and that knowledge does not have a linguistic form from the very beginning.

Before we are able to understand the use of non-linguistic systems of representation in thinking we might first start with the more familiar case of using linguistic expressions for representing insights. In the complex interplay of meaning-giving and intuitive acts, the usual first problem is to adjust the expression to the intuition, i.e. to find the right expression. Only the correct expression will later allow others to know what state of affairs one is intuiting.

We know about the right way to express our insights not always in a very clear manner. In trying to adjust the expression to the intuition we have, we often only feel that one expression is closer than another to "what I had in mind". We learn about the use of words in our community and are often unable to give information about the exact grammatical and semantic rules why one wording fits better to what we mean than another. ${ }^{8}$

Let us now come to the level of understanding: We are able to interpret the language used by others as words and sentences that point to the intuition usually connected with these sentences. Thereby we can gain a clear idea of the intention of others on the states of affairs they utter and perhaps also have in intuition. But we do not take the insight of the other for granted, since at least we know what we have to do to gain our own insight.

In this view of a theory of non-linguistic thinking, language is only a special case of symbolic systems used for thinking. We are able to create a language representation of cognition that can be used in our own further thinking about the situation, and it can also be used for communication with others.

But even a shared opinion is not yet intuition of the intended state of affairs. Cognition - understood as an intuition of these states of affairs - is, in contrast to language representation, more basic, original, and independent. With the help of language we are able to conceive the same state of affair that we have had intuitively before, and this is possible even in the absence of intuition. This revitalization of cognitive intentions allows also for modification and conclusions, and this is the basic function of a symbolic system of representation.

7. For Husserl's theory of meaning, $c f$. the I. and VI. Logical Investigation. For the theory of categorial intuition, $c f$. Ch. 6 of the VI. Logical Investigation and Lohmar (2002).

8. Coming back to the theme of "rightness" of appropriate expression: As the sign-meaning relation is based on association (as well as the relation Anzeichen-Angezeigtes), the meaning is associated with the sign used for expression and the connection is intuitively felt (Hua XIX/1, 36 ; Husserl 2001, $\$ 4$ ). The orientation of this process of adjusting language expression to intuition of states of affairs is easily grasped in the corrections of our language expressions in the case that they do not exactly fit what we are meaning. 
If a system of representation also allows for communication - like language does - this is an extra feature in comparison to its basic function. Hence, it is worthwhile to consider these systems of representation at their basic level, i.e. on the level of solitary thinking, without directing our attention to the communicative function of language.

In opposition to the widespread opinion that thinking is closely bound to language, I would like to show now that Husserl's analyses of the relation of intuition in knowledge and the connected act of meaning-giving leaves room for alternative conceptions.

\section{What are the alternatives for symbolic representations in non-linguistic thinking?}

What are the alternatives we can use for symbolic representation? I will name three types with their performance and their characteristic limitations. This list does not claim to be exhaustive.

1. Language and national codified gesture languages (ASL, etc.).

2. Non-codified gestures together with mimics and pantomimics, this is a hand \& feet communication system I will come back to later.

3. The system of scenic phantasma consists of series of pictures in our imagination sometimes uniting to a kind of video clip of past and future events combined with feelings. It is suitable for the representation in solitary thinking but it cannot be used for public communication. Scenic phantasma are to be found in our daydreams.

The first two modes are usable for communication as well as for solitary thinking, while the third mode can only be the basis of solitary thinking, not for communication.

Before I go into the details of non-linguistic systems of representation, I would like to sum up some facts about the relation between the intuition of states of affairs and the different modes of symbolic representation in which we think about these facts. Generally, the connection between language and thinking is not as narrow and firm as we tend to believe. Not only can we express our insights in different languages, but we can also think in a language other than our mother tongue. Most of us are familiar with the following experience: After spending some days in a foreign country, where a foreign language is spoken with which we are familiar, our thinking takes on the form of this other language. This example shows that the level of language is only on the surface of the whole phenomenon of thinking.

But do we need a level of symbolic representation at all to think? I think so, because we can hold on to the intuition of states of affairs only for a short time. After this we must have a symbolic medium to hold on to the contents of our cognition — but it must not be language. 
This symbolic carrier of a conviction is the presupposition for the three essential performances of thinking: (1) the ability to awaken and to retain in mind the same object of cognition; (2) the ability to engender other cognitions from this one; and (3) the ability to manipulate our future possibilities. These central performances allow me to manipulate the possible future of an object or event in different situations, ponder possible consequences, obstacles, and alternative solutions to problems. Essentially, thinking is an active treatment of the contents of our cognition.

Thus thinking must have a medium of symbolic representation. But this medium needs not be language. Yet language gives us a hint at the most important feature of such a system of symbolic representation: I must be able to produce the material carriers of symbols at any time. For example, I must be able to produce spoken or written words at any time, either in public speech or in inner speech. I am only able to think if the symbolic carrier is ready at hand all the time. This carrier must achieve its meaning in a meaning-giving act based on the intuitive cognition. This is true for language and for all non-linguistic systems of representation. In this regard, the use of non-linguistic symbols also follows the pattern of Husserl's theory of meaning.

Thus, we may conclude what we already know: Language is a usable carrier of cognitive meaning; it makes thinking and public communication possible because I can speak loudly any time; and in regard to inner thinking, I can let my inner voice function as the carrier of thinking. But our conclusions can also go beyond this trivial insight because I now know at least the minimal requirements of symbolic systems useful for thinking. Hence, I must be able to produce the carrier of symbols at any time - either in inner or in outer sensibility. Thus, there can also occur internal carriers of meaning that allow for thinking but do not allow for public communication. And there may also be carriers of symbols that allow for both, such as language, gestures, and pantomime. So it is obvious that language need not be the carrier in all these cases; there are always alternatives.

Which alternative non-linguistic symbolic systems do we have up to now? If you recall, our non-complete list starts with: 1. codified gesture-language; 2. non-codified gestures together with pantomime and onomatopoeia (I called this the hand \& feet system of communication); and 3. scenic phantasma together with emotions. In the following, I will concentrate on the last two systems, also in order to work out some striking similarities between them in the end.

\section{The hand and feet system of communication}

Let us start with a short characterization of the hand \& feet system of communication. A simple example will show us that we usually underestimate our ability to communicate with gestures and pantomime. Imagine being in a foreign country, not being able to speak the local language, and having to go to the airport. I meet a cab driver whom I need to inform about my urgent wish, but without the use of the local language. In a situation like this, we 
immediately start communicating our wishes with the help of gestures, onomatopoetic means, and pantomime. We point to the driver and make a pantomime of steering the wheel, we imitate the sound of driving car, then after pointing to ourselves we pantomime running with luggage and in the end imitate the sound and the movement of a plane starting.

This behaviour is quite revealing of our non-linguistic systems of representation: We start without any hesitation and are very certain about our attempt to communicate in this way. This unreflected certainty reveals that this non-linguistic mode of communication is all the time alive while we use language, for we do not have to wonder about the "how" of this gesture-pantomimic-onomatopoetic communication. We do not wonder whether it may work at all, we simply use it.

This kind of communication is embedded in a common practice and its demands. ${ }^{9}$ It works with people of other cultures, of a higher or lower degree of development, and it can be easily corrected and refined because we are in the context of common action, allowing for an ongoing mutual correction. To understand our trust in our non-linguistic abilities of communication, we might also think about the situation in which ethnologists meet a tribe that speaks an unknown language. Based on the hand \& feet communication we can start a common practice like eating, drinking, and sleeping - establishing a non-linguistic communication that entails mutual correction and a growing part of spoken communications, the words that we learn by this proto-language.

Such non-conventionalized forms of starting communication are always exceptional and transitory, because usually a codified system of communication will be established quite soon in common practice. Either gestures or elements of both languages will be used and mutually accepted, and thereby a new and connecting convention is established. This is part of a universal anthropology: Rules for everything are established spontaneously through communication in every community. Thus, the non-conventionalized "beginning" forms of communication quickly put an end to themselves by establishing conventions or taking up the meaning of words by understanding.

\section{The system of scenic phantasma}

The hand \& feet system is an example of a non-linguistic system of representation for public communication. Now I turn to non-linguistic modes of thinking that are only useful for solitary thinkers and that can unfold in the absence of any communication.

It seems to me that in series of imaginative pictures and in daydreaming we are using scenic phantasma as expressions of our wishes and fears and that they function as representations of cognitive contents. It is always a state of affairs that we wish for or are in fear of. But we do not only express our preferences,

9. I agree that in this situation there is also a presupposed basic similarity of our life-worlds; for example, that there are airports, cabs, drivers, etc. But I do not think this to be problematic. 
our urgent wishes, and our views of the state of affairs by these means. It will turn out that daydreaming is also a kind of response to a problem, a mental action, a mental manipulation of the problematic situation that might lead to a solution until now unthought. My thesis is that series of phantasma and daydreaming are an old mode of thinking still working in our consciousness.

To work out this hypothesis, we will have to ignore for a while some other theories about the status of phantasy in daydreaming. There might be objections to our very "reasonable" interpretation of daydreaming from different points of view: From a liberal-phantasy point of view, our phantasy is usually completely free in the formation of daydreaming and therefore cannot be of any use when it comes to the serious and important problems of everyday life. But some sober reflection and self-observation will convince us that we are not completely free in the formation of our daydreams. From a part-part point of view, we might suspect that we are free in the formation of our positive and pleasant daydreams but passive in the formation of our daydreams about lasting fears. This is not the case either: in both cases I experience myself to be bound. From a psychoanalytic point of view, we might suppose that all the contents of our daydreams are closely bound to our individual experiences just like our dreams are bound to them. But as I have already mentioned, we will have to ignore these theories about our daydreaming for a while.

In my view, in daydreams we are playing out possible solutions to a problem, i.e. we are mentally testing our options, their usefulness for a solution, and their respective consequences. This "life" of scenic phantasma constitutes a great and important part of our conscious life. ${ }^{10}$ Some examples would be: A) Worries about urgent challenges or uncertainties that make us sleepless at night. B) There are many phantasies of having success. C) I would also like to mention empirical-psychological research that suggests that most grown-up males think of sex every few minutes, and the mode of this thinking is definitely not conceptual. In these scenic episodes of our conscious life, the linguistic expressions emerge in the background in favour of pictorial elements.

We also know that most highly developed mammals can dream. While dreaming they show first signs of an attempt to act and emotions. We might interpret these phases of their sleep as dream episodes prolonging wakeful states of action and aims. ${ }^{11}$

We might therefore claim that a system of representations on the basis of scenic phantasma combined with feelings is operative in higher cerebralized mammals up to primates in dreams and wakeful state in the same way as in humans. This claim, however, only indicates an important consequence that stems from my investigations into the systems of representation in humans.

10 Cf. Lohmar (2010).

11. Higher cerebralized mammals are also capable of daydreaming: they can identify events with relative precision and often visually replay difficult former or future situations they were confronted with. An example of a rat that has to pass a labyrinth to get food is a good case in point. The recent research in working groups around Matthew Wilson (MIT) using single neuron tracing shows this in a quite impressive way. I have delineated this in Lohmar (2012). 
But nevertheless this hypothesis about animal thinking is not mere fancy or an arbitrary phantasy because, as the phenomenological analysis reveals, it characterizes an important dimension of our own thinking. Thus through these analyses we might find out in which way we are still thinking like animals. In the present analysis I will not concentrate further on the theme of animal thinking.

Another important element of non-linguistic systems of representation are feelings, functioning in the framework of scenic phantasma. ${ }^{12}$ Emotions can easily grant the most important request for a system of representation as we can have them in an actual situation and we can "produce" them (although not arbitrarily) also in the absence of the intuitive situation, i.e. only through phantasy. For example, the feeling of fury might move me violently in a certain situation and the same feeling can also reappear in mere thinking of the same situation later on. In both cases the feeling "tells" me something about the value of this event, for it is a part of my inner "expression" that has a certain meaning. In thinking about a nice experience the pleasant feeling "means" the desirable quality of the event. ${ }^{13}$

Daydreams perform in their way a consistent representation of our everyday longings, wishes, and fears. Thus they mirror somehow our personal order of significance between the two poles of events that should never happen and that should happen at any costs. And they do not ask for a refined psychoanalytical hermeneutics. Daydreams differ strongly from nightly dreams, as they are respecting the identity of objects, causality, and their order in time. Also, from this point of view, they can be accepted as being a "reasonable" thinking activity dedicated to serious problems of past, present, and future reality. The framework of our order of relevance in possible events makes us also understand better why special daydreams must be experienced ever and ever as long as the urgent needs, tasks, and oppressing fears remain the same. But daydreams do not repeat everything unaltered, we have to be attentive to small modifications in these repetitions that represent a real option in real action.

To give an example: Had I been pressed hard by an impertinent and aggressive guy, and had I given way to his demands due to the circumstances, this annoying situation will furiously re-emerge in my daydreams many times. But this repetition of the situation in my daydreams does not leave them identical. Sober reflective self-observation makes me realize small variations of my behaviour - and quite slowly, in some further replays, it leads me to the right solution to get rid of his aggressive demands: This would have been the right reaction; had I done this, it would have stopped him! Nevertheless, this insight is unre-

12. In my view we cannot interpret emotions as an independent system of representation because we always have to presuppose another kind of representation in which we have in mind things or (real or possible) events that are objects of feelings.

13. We might suppose that also most animals have feelings as part of their system of representation. It makes no sense to have objects and properties of them if you do not have feelings to evaluate these objects and events, this is the way to actively make use of our experiences with them. 
al and accompanied with a regretful feeling since it cannot change the past, but is nonetheless a kind of action on future reality: It enables me in a similar situation, if it were to recur, to act appropriately and to resist the unjust demands. ${ }^{14}$ The same is true for events I am anxiously expecting.

Therefore the scenic-phantasmatic mode of daydreams allows for an interpretation of daydreaming as an old mode of thinking. If I am worried in the mode of daydreaming then things and persons are occurring in pictorial representation and language shifts into the background. The content of my worries is represented in scenic phantasma, but every time with small modifications. And in these modifications we sometimes realize successful solutions to our problems. For example, winning a lottery will easily solve the pressing financial concerns, but it is unlikely to happen and does not give me the feeling of confidence; working hard or suffering for some time from some privations will work as well, and this idea gives me much more confidence in its success. This shows clearly the function of daydreaming as a non-linguistic mode of thinking that can, so to say, lead to solutions of everyday problems. Daydreaming must not be interpreted as an evasive regression to a childish mode of handling problems only in phantasy. ${ }^{15}$

Besides my insistence on the reasonable character of non-linguistic modes of thinking, I will not deny that we humans, in turning back from our inner life of scenic phantasma to other members of our group, immediately will switch to a linguistic-mode of communication. This shift, however, only expresses what was already found at the level of non-linguistic thinking.

Seen from a systematic point of view, there is only a limited set of themes that we have to be able to think about. 1. Objects, their present and future states, and use (for example as a tool), as well as their value in my personal estimation and their value in the view of the community. 2. Events in present, past, and future, their felt value and their probable consequences. 3. Other persons with their sensations, feelings, convictions, and their practical intentions related to me and other members of the group. - I shall leave it to the reader to find examples for the first two themes. Meanwhile, I will concentrate on the last group of intentions of other persons.

It seems difficult to imagine a scenic image of the character of a person and of his or her probable behaviour towards me, especially within complex constellations with others involved in action. But scenic phantasma offer a simple solution to this apparent difficulty. In remembering a brutal former classmate, I see his face looking at me with evil eyes, with clenched fists, and ready to give

14. The result of this active manipulation of future is a kind of ideal picture of the solution of problems like this under given circumstances. Nevertheless this result of successful manipulation of a flop (reframing) is often communicated afterwards as a true story to cover my failure to stand the unjust criticism of my boss, a confrontation in traffic, etc.

15. We might also stress that non-linguistic modes of thinking in the scenic-phantasmatic system are not as quick and effective as linguistic modes of thinking; it will always take some repetitions to find a way to solve the problem, even if the scenic representation of an event is running in a compressed speed-mode. 
me a beating. But this "image" is not simply an image of him; it is a characteristic scene within which I am present, writhing with pain from his beating and in fear of his further beatings, and in the background there is a group of "friends" not helping me. This scene presents central aspects both of his character and of his future behaviour within a social context.

But the scenic presentation of the attitude and behaviour of a person needs not be so one-dimensional as in this case, since normally there are multiple facets of the character of other persons that we are able to present. Thus the question arises: How can I think a multitude of (changing) attitudes in a scenic mode? Now, think of a colleague with whom you work together successfully in most cases, but who occasionally appears with an air of high-nose arrogance. Both "faces", i.e. both aspects of his character, may be represented in a scenic phantasma, one after the other, or, even, as mixed in a changing way, which results in an uncertain base for your plan-making. The modal character of possibility and uncertainty is thus present in the changing and merging faces of your colleague. We might even interpret this changing image as a non-linguistic form of the logical "or". His attitude towards other persons and his options in a changing situation may be represented in a short but eloquent side-view on others, etc.

Since the value and the usefulness of objects can change, this may be also reflected in characteristic scenes. For instance, if I own a car that usually breaks down and thus has to be towed off and repaired, the characteristic scene within which I am positively excited about my car is modified, and converted to one that is negative. The emotional aspects of this bad experience are especially mirrored in the scene characterising this object: I no longer imagine the car with the joyful expectation of reliable use, but with the cheerless expectation of future harm, expense, and inconvenience. In this way, the variations of characteristic scenes, i.e. characterising persons, objects or events, unfold by means of similarity semantics. ${ }^{16}$

With our analyses, the significance of language for human thinking is delimited in a clear way. Language is by far not the only possible means of thinking and, moreover, it is not the only system of representation operative in human consciousness. The real basic performances of cognition and our conception of reality are based on more simple non-linguistic systems of representation that are still operative in our mind. Public language and the concepts it uses turns out to be only a very superficial layer of the whole performance of thinking.

16. Besides my emotional valuing of objects and events, I can also have a scenic phantasma which entails valuing reactions of others on my planned future actions. If I am pondering problematic plans of my future behaviour, then suddenly close friends or relatives may show up in the characteristic scene, somehow looking sorrowful but also with sympathy at me. Thereby the valuation of my planned actions in the view of the community is articulated. That means that even persons sympathizing with me have serious considerations. Their expressions of sympathy and worry at the same time give me an important hint about the valuing and the probable reactions of others to my plans. 
The reason why we are able to understand each other even if we do not speak the same language is that we in fact are thinking the whole time also in a parallel mode of thinking that is non-linguistic, based on an easy similarity semantics, that is, based on similarity of the symbol used with the meant object/event.

In my presentation I have concentrated on establishing the idea of non-linguistic thinking in humans, but we started with problems of communication with national languages. And we see that there is quite an easy solution for this problem caused by naturally developing differences between national languages. Remember the non-linguistic hands \& feet communication using non-codified gestures, mimics, pantomime, onomatopoeia (and further means, such as hand-theatre). I would suggest that all humans are able to use these non-linguistic systems of representation for communication. Thus we may ask: Is there a special way through which humans learn how to use this way to communicate?

Let us take a step back and try to find the common structure of the systems of representation used in the scenic-phantasmatic system and the hand $\&$ feet communication. We recognize that both ways of representing ideas are using a similarity semantics. That is, all means of representation, all symbols of these two non-linguistic systems of representation, are somehow "similar" to the objects represented. This is quite an unusual characteristic of semantics, which makes an important difference in regard to the semantics of national languages. To clarify this point, I will turn to the very basics of semantics of usual languages.

In normal conventional semantics of national languages, it takes a long time to learn the connection of a language sign and its meaning. But for children learning the language of its community it is quite easy because it corresponds with the strong wish of a child to adjust to the communication that grown-ups use. It wants to become a "full member" of the community, and it is fun to adjust to the rules. Thus, normal conventional semantics is always related to a community that agrees on these conventions and acts in a normative way to have meaning reliably connected with expressions.

Thus, conventional semantics are always to a certain extent artificial. Neighbouring national languages differ because language is an important part of our identity. My special language is not only a distinct sign of my belonging to a particular community, but it also indicates the difference from us to the other communities.

By contrast, the similarity semantics of non-linguistic systems of representation neither rests on agreement nor on rules accepted by a communicating community. ${ }^{17}$ In this regard, similarity semantics is much more natural than

17. The relation of similarity seems to be very easy. We tend to believe that we are able to simply "perceive" similarities; for example, between father and son, trees, and sheep, etc. As phenomenologists, we are also convinced that this ability is the basic performance to establish the intuition of common traces in a certain type of things, like in trees (Wesensschau). But this does not imply that the facility of recognizing similarity is already established in the earliest age of children. This would also be a theme for investigations in developmental 
conventional semantics: It is based on the similarity of the symbol and the object it designates. We recognize this in the hand \& feet communication: If I imitate running and carrying a case, it looks similar to a real event. If I imitate the sound and the movement of an airplane, it is similar to the sound and appearance of this event. This is the reason why I do not need to be trained in hand \& feet communication: It rests on a natural similarity semantics that it has in common with the very basic scenic-phantasmatic system of representation in non-language thinking.

Similarity semantics is also the basis of the system of scenic phantasma in non-linguistic thinking. This thinking has either no or only a few linguistic elements and it immediately grasps what is meant by similarity. We have realized that not all thinking is going on in the form of language and there is a profound layer of non-linguistic thinking using the same similarity semantic as an elementary form of gesture communication. Therefore, there are good chances to begin and maintain intercultural understanding! ${ }^{18}$

\section{Bibliographical references}

Hussert, Edmund (1969). Formal and Transcendental Logic. The Hague: Martinus Nijhoff.

- (2001). Logical Investigations. Vol. I and II. London: Routledge.

Lohmar, Dieter (2002). "Husserl's Concept of Categorical Intuition”. In: D. Zahavi / F. Stjernfelt (ed.). Hundred Years of Phenomenology. Dordrecht: Springer, 125-145.

- (2005). "Leiblich verständigt sein. Über die anthropologischen Grundlagen des Verstehens anderer Menschen und anderer Kulturen". In: H.-J. Scheidgen and Y. Nakamura (eds.). Philosophie, Gesellschaft und Bildung in Zeiten der Globalisierung. Amsterdam: Rodopi, 125-141.

- (2008a). Phänomenologie der schwachen Phantasie. Dordrecht: Kluwer.

— (2008b). “Denken ohne Sprache?”. In: Ed. F. MatTens et. al. (ed.): Meaning and Language: Phenomenological Perspectives. Dordrecht: Kluwer, 169-194.

- (2008c). "How do primates think? Phenomenological Analyses of a non-language system of representation in higher Primates and Humans". In: Christian Lotz and Corinne Painter (eds.). Husserl and the non-human animal. Dordrecht: Kluwer, 57-74.

- (2008d). "Kategoriale Anschauung. VI. Logische Untersuchung, $\$ \$$ 40-66". In: V. MAYER (ed.). Edmund Husserl, Logische Untersuchungen. Berlin: Akademie Verlag, 209-237.

psychology, which I cannot offer here. My opinion in this regard is the following: We are able to establish our means to recognize and to actively use similarity by experience. That means that we can learn about similarity relations because we have some basic ability to recognize similar elements in different objects. But we do not have to learn from others to use this ability.

18. I would like to thank Saulius Genusias for his efforts to make my English text better, as well to the blind reviewer. 
- (2010). "The function of Weak Phantasy in Perception and Thinking". In: S. Gallagher and D. Schmicking (eds.). Handbook of Phenomenology and Cognitive Science. New York-Heidelberg: Springer, 159-177.

- (2012). "Thinking and non-language thinking". In: Dan ZaHAVI (ed.). Handbook of Contemporary Phenomenology. Oxford: Oxford University Press, 377-398.

Mall, R. A. (1993). "Begriff, Inhalt und Methode der Hermeneutik der interkulturellen Philosophie". In: R.A. Mall and D. Lohmar (eds.). Philosophische Grundlagen der Interkulturalität. Amsterdam: Rodopi, 1-28.

- (1995). Philosophie im Vergleich der Kulturen. Interkulturelle Philosophie eine neue Orientierung. Darmstadt: Wissenschaftliche Buchgesellschaft.

Mohanty, J. N. (1993). "Den anderen verstehen”. In: R.A. Mall and D. Lohmar (eds.). Philosophische Grundlagen der Interkulturalität. Rodopi, Amsterdam 1993, 115-122.

Paul, Andreas (1998). Von Affen und Menschen. Verhaltensbiologie der Primaten. Darmstadt: Wissenschaftliche Buchgesellschaft.

Tomasello, Michael (2009). Why We Cooperate. Cambridge: The MIT Press.

Dieter Lohmar is Professor of Philosophy at the University of Cologne (Germany) and Director of the Husserl Archives Cologne. He has edited two volumes of the Husserliana series: Die Bernauer Manuskripte über das Zeitbewusstsein (Hua XXXIII, co-editor: R. Bernet, 2001) and Späte Texte über Zeitbewusstsein (1929-34): Die , C-Manuskripte' (Husserliana-Materialen VIII, 2006), and is currently editing for publication Husserl's late manuscripts on space constitution. In addition to his multiple articles and edited collective volumes, he is the author of Phänomenologie der Mathematik (Phaenomenologica 114, 1989), Erfahrung und kategoriales Denken (Phaenomenologica 147, 1998), Edmund Husserls 'Formale und Transzendentale Logik' (2000), Phänomenologie der schwachen Phantasie (Phänomenologica 185, 2008) and Denken ohne Sprache (Phaenomenologica 219, 2016). He has been President of the German Society for Phenomenology and is member of the editorial board of the series Phaenomenologica and Contributions to Phenomenology (Springer), as well as the journals ALTER (France), Phänomenologische Forschungen (Germany) and Phainomenon (Portugal).

Dieter Lohmar és professor de filosofia a la Universitat de Colònia (Alemanya) i director dels Arxius Husserl de Colònia. Ha editat dos volums de la sèrie husserliana: Die Bernauer Manuskripte über das Zeitbewusstsein (Hua XXXIII, coeditor: Rudolf Bernet, 2001) i Späte Texte über Zeitbewusstsein (1929-34): Die,C-Manuskripte' (Husserliana-Materialen VIII, 2006), i actualment prepara l'edició dels manuscrits tardans de Husserl sobre la constitució de l'espai. A més d'una gran quantitat d'articles i d'haver editat diversos volums col-lectius, és autor de Phänomenologie der Mathematik (Phaenomenologica 114, 1989), Erfahrung und kategoriales Denken (Phaenomenologica 147, 1998), Edmund Husserls 'Formale und Transzendentale Logik' (2000), Phänomenologie der schwachen Phantasie (Phänomenologica 185, 2008) i Denken ohne Sprache (Phaenomenologica 219, 2016). Ha estat president de la Societat Alemanya de Fenomenologia i és membre del consell editorial de les col-leccions «Phaenomenologica» $\mathrm{i}$ "Contributions to Phenomenology" (Springer), així com de les revistes ALTER (França), Phänomenologische Forschungen (Alemanya) i Phainomenon (Portugal). 